\title{
José de Alencar: um historiador à sua maneira
}

\author{
Marcelo Peloggio
}

\begin{abstract}
O espanto é filho da ignorância; e quanto maior o efeito admirado, tanto mais, proporcionalmente, cresce o espanto.
\end{abstract}

Giambattista Vico

Muitas vezes, ocupando-nos da história nacional, somos acometidos de certa reminiscência, que nem sempre é a nossa. Neste caso, é como adivinhar a presença do elemento que vem de fora, ajustando-o de algum modo à imaginação a ao gosto local. Sobretudo no Brasil, que, após sua independência política, viu-se aberto às novidades da cultura estrangeira; ora, a incorporação desta permite recriar aquilo que chamamos "nação", feita, dizem, de usos e costumes muito próprios.

Essa presença forasteira nas coisas nacionais representa fenômeno dos mais complexos; significa que influi na formação das sensibilidades, de vez que assume importância capital no incremento da ordem espiritual e estética. Daí, num sentido sociologicamente considerado, é também salto que se dá, o mais significativo e amplo. Numa palavra: contribui de maneira decisiva para o aprofundamento de uma visão geral da realidade física e espiritual, social e histórica, visto encarnar a convenção mais grave, que é assimilada pelo grupo até sua presença no domínio da consciência individual, e desta torna à coletiva, confirmando o amplo fenômeno de troca entre o que é particular e universal no conjunto da sociedade.

A história pátria, mesmo a refletir com alto vigor o que considera próprio a uma nação, expressando aí o modo de ser de um povo, não deve perder de vista esse traço do "estrangeiro": a perspectiva que orienta o pensamento político e filosófico, designando a "origem" mesma das comunidades, vistas agora sob outro ângulo. Em outras palavras, já como nações constituídas, naquilo que trazem de mais expressivo e particular. Tomemos um exemplo. 
"(Duby, Georges. Guilherme Marechal, ou o melhor cava. leiro do mundo. Rio de Jane ro: Graal, 1987: 43.)
Na tradição medieval francesa e inglesa há uma personagem histórica, Guilherme Marechal, cuja memória se celebrou numa canção de quase vinte mil versos. Esse "poema, que foi posto em rimas às margens do Tâmisa, constitui um dos primeiros monumentos da literatura francesa". Como toda biografia militar, e apaixonada, reserva destaque às gestas do velho cavaleiro. A narrativa que a decompõe é das melhores: simples, equilibrada, guardando certo lirismo. E, assim, todo esse mundo masculino, em que só "contam os varões", vai pouco a pouco atingindo os fenômenos de mentalidade. A conjuntura se vê como que iluminada inicialmente pela forte presença eclesiástica, que arrasta consigo - formando com ela esse grande painel - os demais elementos. A partir daí, vemos apontar os problemas relativos à linhagem em face da herança filial. Aqui, a amizade varonil; mais adiante, os torneios e o problema da ascensão social na consignação do dote, em ambiente em que se dispunha de "um abundante viveiro de mulheres sem marido", algumas das quais valendo muito dinheiro; e, mesmo, os episódios regulares da economia, como a circulação monetária, visto que, ao menos como informa o mercado matrimonial, "o dinheiro contava tanto naquela época quanto em nossos dias"."

Há uma preocupação, porém: se o vasto poema - encomendado para trazer à vida aquele que foi tutor do "rei menino" - diz a "verdade" sobre o mundo que eram França e Inglaterra no século XIII. Reconheçamos aí uma exigência - imperiosa - porque é surpreendente "ver como é curta a distância que separa das fiç̧ões corteses a realidade que o poema pretende descrever fielmente" *. Ora, todo o problema está menos em lhe asseverar a autenticidade da narrativa (coerente com o que se sabe da época) e mais em propriamente contar: "Quero, apenas, tentar ver o mundo como esses homens o viam".

Que belo e expressivo legado nos transmite Georges Duby ao "retratar" aqueles homens, sua maneira própria de sentir e pensar; a nós historiadores, há muito desacostumados com os recursos vastos da boa escrita, bem como com os da imaginação rica e vivaz.

Um cruzamento interessante então se verifica, precisando o encontro de duas linhas de força, que em certo momento se tocam, e que se reforçam, à medida que descrevem, uma 
ao contrário da outra, seu mais íntimo traçado. De um lado, encarrega-se Georges Duby de, fiando-se na arte literária, oferecer um panorama das "três ordens"; de outro, aparece José de Alencar, expressão máxima de nossa ficção romântica, no trabalho criterioso de sacar nas crônicas históricas o elemento básico do passado colonial, a fim de que atue como pano de fundo na armação de seus romances. O que queremos dizer é mais ou menos isso: aquele, o historiador francês, parte da imaginação literária em direção à histórica, e, nessa empresa bem-sucedida, ajusta a nota estética ao discurso historiográfico, ao passo que o ficcionista brasileiro converte os fatos nacionais em representação literária, de modo a "dramatizar a história descrevendo a cena onde se passaram os fatos mais importantes, e apresentando ao vivo os seus personagens e a sua decoração"*

Com efeito, o que persiste em um e outro não é senão o desejo de poder fixar uma identidade histórica; essa idealidade que não os afasta da "verdade severa" dos fatos. A imaginação, assim, recobre a história partindo de acontecimentos reais - a serem tratados quer pela aridez do documento (cartas, decretos, relatórios), quer pela linguagem figurada da obra poética. O que não impede o conhecimento do passado mediante uma das formas pelas quais se lhe representa o conjunto de eventos. Portanto, a imagem que os expressa, como dado elementar na história cultural dos povos, constitui verdade a modo de traço enunciativo. Sua inteligibilidade não se liga a uma lei geral dura e restritiva, quer dizer, o curso da realidade humana não estará sujeito ao a priori dos sistemas deterministas. É que o senso de imaginação tem aí, por meio de uma operação transfiguradora, papel decisivo. Assim sendo, diz Alencar:

Talvez me censurem por isto e julguem que desci da verdade à poesia; tenho porém a consciência de que a imaginação aí não faz mais do que dar um corpo aos objetos que o espírito vê com os olhos d'alma, e ligar os diversos fragmentos que se encontram nos livros para fazer deles um quadro ou uma estátua. Demais sou historiador à minha maneira."

De acordo com Fábio Freixieiro, Alencar "tenta apropriar-se de uma cultura histórica, com transcrições severas de fontes, para compor sua novelística, e dar-lhe até um valor relativamente documental"*. Mas em que medida os romances alen-

"(Alencar, José de. "O Rio de Janeiro" (prólogo). Em: Frei. xieiro, Fábio. Alencar: os bas. tidores e a posteridade. $2^{\mathrm{a}} \mathrm{ed}$ Rio de Janeiro: Museu Histó. rico Nacional, Coleção "Es. tudos e Documentos", v. IV, t. 1, 1981: 110.)

"(Freixieiro, Fábio. Alencar: os bastidores e a posteridade. Ob. cit.: 6.) 
"Ver White, Hayden. Meta. história. A imaginação histó rica do século XIX. São Pau lo: Edusp, 1994: 11-56.)
(Veyne, Paul. "A história conceitual". Em: Le Goff, J. e Nora, P. (org.). História: novos problemas. Rio de Janeiro: Francisco Alves, 1976: 66.)

"(Ivo, Lêdo. "O apelo da flo resta". Em: Alencar, José de. O guarani. São Paulo: Círculo do Livro, s/d: 341.) carinos, sobretudo os que mais fundo avançam no passado colonial, podem influir no curso amplo da investigação histórica? De fato, nota-se o desconforto de alguns setores ante o emprego de fontes mais estéticas que “documentais". É o que mais cria barreiras ao avanço do conhecimento historiográfico, tanto na organização quanto na exibição de dados que lhe seriam de fundamental importância (sua "pertinência”). Queremos deixar claro, de antemão, que não concordamos com esse critério de seleção das fontes. Tal postura é injustificável, em vista do caráter imaterial (pretérito) dos episódios e de sua relativa "falsidade". Toda essa idéia, alçada sob grande perspectiva, de que o inventário maciço da realidade é, sem reparo, tão objetivo quanto esta também deveria refletir o concurso infinito dos acontecimentos. Assim, os fenômenos de história, os "mais importantes”, ganharão destaque em razão de sua natureza diretiva, agravada pelo "signo monovalente" do positivismo.

De há muito que a história situa o problema da interpretação do seu campo de análise à luz de um mesmo e único “ponto de vista”. Talvez por isso - e não obstante os esforços de fixação de um princípio geral e diretor - viva o eterno vaticínio da reinvenção. Donde se conclui que a representação dos eventos, ou melhor, de uma dada "congérie de fatos estabelecidos e inferidos”, designa uma ficção da realidade como "estória de tipo particular"*.

É porque a história se acha, à maneira de Sísifo, em eterno recomeço, a deslocar desde então sua grande pedra: ela não deduz de si toda a existência no fundo original da vida. Pois o que lhe cabe (no que os eventos têm de filosófico) é oferecer uma "explicação" do mundo, a qual, ainda que provisória, é capaz de mostrar que vida e mundo são, de algum modo, inteligíveis. Mas "a mágoa do historiador é nunca poder alcançar o inatingível”*. Em suma: a história é, pois, o conhecimento parcial da realidade na linguagem em devir.

Um crítico pouco lembrado, Lêdo Ivo, diz com razão que, "em Alencar, como em todo grande criador, o documental é utilizado para servir a uma realidade nova: a realidade estética de seus romances ou poemas em prosa"*. Se Alencar, por um lado, no sentido oposto ao de Duby, propõe o tratamento artístico do campo histórico, por outro, vai ao encontro desse autor: há, nos romances alencarinos, toda uma lógica de re- 
construção imaginativa do passado "real”. Pois é justamente aí que literatura e história encontram terreno fértil, recorrendo uma à outra, já que importa menos se os documentos retratam fielmente a realidade que levar a efeito seu mais elevado propósito: fazer da reminiscência mesma um ato puramente enunciativo, em que conta “a poesia em toda a sua beleza plástica e ao mesmo tempo a história”* Daí que as coisas se tornam, incessantemente, à luz de tal e tal eflúvio poético, dado que a história é, toda ela, linguagem em devir.

Mas porque elas desconcertam e assustam, como objetos que são da literatura, encontram-se a meio caminho do real e irreal, e, muitas vezes, escapam à compreensão lógica, chegando mesmo às raias do fantástico de que fala Todorov*.

Em verdade, o escritor não busca em outro lugar, senão em uma determinada cultura, os motivos que o levam a exprimir sentimentos e idéias, fazendo passar, "através do prisma do meio social concreto que nos engloba”, aquilo que sua imaginação foi buscar algures. Portanto, o sistema de referência que utiliza - ainda que extravagante - é código válido; significa dizer que o entendimento de qualquer cidadão do mundo, suficientemente letrado, pode penetrá-lo; pode mesmo divisá-lo, se “incompreensível”, nas vastidões pouco iluminadas do campo mental: o "aparelho" de Kafka, a "múmia falante" de Poe, ou ainda o "cavalo encantado" e o "anão Escaibar" de As mil e uma noites. A ação mais direta que o real exerça sobre a vida psíquica do grande autor não lhe arrefece de modo algum a percepção aguda acerca da vida social, política e ideológica. E a partir do entendimento largo e profundo da realidade objetiva, podemos avançar do senso concreto das coisas até sua "depuração" (concreto pensado), cumprindo-lhe a existência na mais alta esfera do pensamento filosófico; em sentido elementar, denota a passagem do que é local ao universal ${ }^{1}$ (o que explica aí todas as reminiscências não-nacionais).

'É preciso esclarecer: tal universalidade "não é de modo nenhum o produto do conceito que pensa separado e acima da intuição e da representação, e que se engendra a si mesmo [tese idealista], mas da elaboração da intuição e da representação em conceitos". Trata-se de "um produto do cérebro pensante que se apropria do mundo [...]”. (ver Marx, Karl. "Introdução à crítica da economia política”. Em: Ospensadores. 4a ed. São Paulo: Nova Cultural, v. 1, 1987: 17-ss). Em verdade, "todas as questões metafísicas que a filosofia escolheu como tópicos especiais vêm das experiências do senso comum" (Arendt, Hannah. A vida do espírito: o pensar, o querer, o julgar. Rio de Janeiro: Relume-Dumará, 1993: 61).
"(Alencar, José de. "O Rio de Janeiro". Ob. cit.: 110.)

'(Todorov, Tezvetan. As estruturas narrativas. $2^{\mathrm{a}}$ ed. São Paulo: Perspectiva, 1970: 147.66.)

'(Bakhtin, Mikhail. Marxismo e filosofia da linguagem. $6^{a}$ ed. São Paulo: Hucitec, 1992: 112.) 
"(Freyre, Gilberto. "José de Alencar, renovador das le. tras e crítico social". Em Alencar, José de. Otronco do ipê. Rio de Janeiro: José Olympio, 1957: 13.)

"(Bakhtin, Mikhail. Marxismo efilosofia da linguagem. Ob. cit.: 114 .)

(Ricoeur, Paul. Tempoe narrativa, t. 3. Campinas: Papirus, 1997: 331, grifos do autor.) 
Em contrapartida, será apenas considerada a obra literária que tenha fortes laços com a vida de relação. Visto o problema sob esse ângulo, o escritor, em razão de um julgamento cuja tendência é a noção árida da própria vida, ou alarga sua nomeada, escandindo a realidade para o incremento de uma "visão homogênea", ou vê agravarem negativamente sua alegoria, através da qual designa um mundo em movimento em contraposição a outro estático, um de coloração forte a outro de tipo "transparente". Parece ser de Hegel a opinião de que a realidade constitui objeto especioso, que se manuseia com alguma habilidade para o enriquecimento geral de suas vias, a modo de "adaptar a vida à arte e dar-se com prazer à ilusão de uma existência estético-utópica”**.

Encarando esse problema, no que delibera em conjunto, tem-se uma noção mais abrangente, senão genérica, da realidade humana. Com efeito, a avaliação de uma obra literária não deve restringir-se a seu aspecto formal: percorre-a, pois, a "estrutura profunda". Ora, designá-la como sendo "de todos os tempos", implica reconhecer-lhe a reminiscência local como universal, podendo tornar-se, mundo afora, a peça eficiente dos movimentos artísticos (como o Werther, de Goethe). O objeto literário penetra, assim, a esfera das coisas concretas, ligando-as a toda humanidade, isto é, à medida que as põe à volta com recursos internos vastos.

Cumpre aqui um esclarecimento: não tomamos a investigação literária à luz do procedimento científico de análise e descrição da vida; ainda que ancorada à tradição cultural, não lhe devemos ter uma noção simples. Nela, o escritor alça a vista para um horizonte de projeções íntimas; organiza, dentro de uma estrutura lógica, os "fragmentos de percepção e de conhecimento" retirados do viver cotidiano." Eis que se convida à celebração do mundo como instância enunciativa, que é infinitamente diferenciada na mais alta esfera da criação semântica: "o poeta destrói os símbolos fixos do dogma a fim de renová-los”* Ou seja, é a partir daí que se dá curso à produção da historicidade como devir: as reminiscências deliberam, com pleno êxito, as energias da criação no ego volitivo. Mas é preciso lembrar que:

os fatos [estéticos ou históricos] e a sua explicação ou interpretação formal aparecem como a "superfície" manifesta ou literal do discurso, ao passo que a linguagem figurativa, utilizada para caracterizar os fatos, indica um sentido estrutural profundo."

"Candido, Antonio. "A personagem do romance". Em: $A$ personagem de ficção. São 61-ss.)

'(Quinet citado por Wellek, René. Conceitos de crítica. São Paulo: Cultrix, s/d: 157.)

'(White, Hayden. Trópicos do discurso. Ensaios sobre a crítica da cultura. São Paulo: Edusp, 1994: 127.) 
"(Ivo, Lêdo. "O apelo da flo. resta". Ob. cit.: 343.)

"(Lousada, Wilson. "Alencar e "As Minas de Prata". Em: Alencar, José de. As minas de prata. Rio de Janeiro: José Olympio, 1951:11-8.)
Designam, por meio dessa região afastada, o que é ao mesmo tempo particular e universal para o âmbito da narrativa histórica ou romanesca; atribui-se-lhe o sentido de realidade (ou de irrealidade) mediante o qual um e outro fator de compreensão doa às coisas um "novo" significado; a transposição da vida social e do espírito, seja ela "objetiva” ou “imaginária”, encarnará, de agora em diante, uma exigência da composição, pois toda e qualquer visão aguda suplanta os modelos na tradição literária (é o caso de Machado de Assis e seu Memórias póstumas de Brás Cubas). Porque, "em arte, a continuidade resulta das rupturas e transgressões, e não das submissões automáticas"*

Na literatura de ficção de José de Alencar, há uma obra que, se não é a mais importante, pode ser considerada fundamental, nessas condições, para o real entendimento de outras de mesmo teor: As minas de prata.

Tudo aí é grandioso. Pode-se mesmo dizer que há, em $A s$ minas de prata, como que o melhor da ficção alencarina. Sua composição é apoiada por estrutura narrativa coesa; a trama, habilmente conduzida, ordena-se criando uma ambiência vária e riquíssima. É o que explica o fato de as cenas, em dado momento, permutarem-se, sem lhes avultar o menor sinal de insuficiência semântica. O estilo é largo e primoroso, e o claro domínio sobre o desenvolvimento da narrativa impede que a trama avance ou recue em demasia por conta de suas voltas e reviravoltas (o que comprometeria o ir e vir das cenas). Daí ser As minas de prata livro de grande engenho, já que revela uma coerência estética profunda. Constitui mesmo referência fundamental para a história da literatura romanesca.

A história é simples e comandada, direta e indiretamente, por um "triângulo": porque é graças a ele que boa parte das ações irá se desenvolver. O assunto do livro é o famoso roteiro das minas de prata, cuja descoberta se atribui a um aventureiro, Robério Dias. Lembrando o que disse Wilson Lousada*, é em torno de uma incansável busca pelo roteiro das minas que as mil páginas do romance, que "é ação do princípio ao fim”, gravitarão. Por conseguinte, é sobre esse núcleo principal que apoiamos o "triângulo".

Em cada um dos três vértices, sem mais, fixa-se uma personagem. No que está voltado à base, encontramos Estácio, o 
herói do romance e filho de Robério Dias. Jovem metido em pobreza pecuniária, mas abastado de grande coragem e honra cavalheirescas, tem pela frente dois desafios: reabilitar a memória do pai, livrando-o da acusação de "falso" e "embusteiro" (quer dizer, de ter inventado a existência das minas), e superar o preconceito social para casar-se com Inês de Aguilar, que é "princesa inacessível”, já que é nobre e rica. Para tanto, faz-se mister a recuperação do valioso roteiro.

Com efeito, é graças aos dois ângulos da base, um e outro "cerebral", que notamos a presença de um "fator dinâmico", típico do romance alencarino, a que Antonio Candido chama de "desarmonia", designando, "sob a forma mais elementar, [...] o choque do bem e do mal"."

De um lado, surge a figura cadavérica do licenciado Vaz Caminha, "o mais sábio letrado da cidade do Salvador". Representa, no caso, o pólo positivo do drama. Tutor, "pai espiritual e amigo" de Estácio, devota-lhe total desvelo ao amparo e educação. É também o "homem que sabia viver", penetrando o meio social à cata de alguns favores fundamentais. Mas há nele, em contrapartida, o "advogado seco e dogmático", cuja "necessidade de ganhar os meios de subsistência tinha criado essa personalidade, que, sendo a menos verdadeira, era a que a todos se manifestava"*.

Divisa-se, em plano oposto, a inteligência fina do padre Gusmão de Molina, o "visitador" da Companhia de Jesus. É velhaco e talvez uma das figuras mais interessantes de todo o repertório alencarino; denota o lado malvado da intriga e seu ponto alto. Este, em nome da Ordem que representa e da glória pessoal, busca, de todas as maneiras, apossar-se do manuscrito de Robério; aliás, o senso prático que tem das coisas o faz previdente, ainda que na pele do arrogante Vilarzito: "O futuro é de Deus, o passado dos mortos. O presente é a vida"*.

Essas três personagens, que consideramos as principais, como que "atraem" aquelas cuja importância na trama é relativa: Cristóvão, Dulce, Gil, João Fogaça, Joaninha. Pois os lances que a podem decidir têm sua origem nas três primeiras: em Caminha e no padre Molina, sendo Estácio a "ponta da ação".

Diz-se que o romance é histórico, por combinar o tipo criado na imaginação com os que existiram em carne e osso,

"(Candido, Antonio. "Os três Alencares". Em: Formação da literatura brasileira: momen. tos decisivos, v. 2. Belo Horizonte: Itatiaia, 1981: 230.)

'(Alencar, José de. As minas de prata. Ob. cit.: 77.) 
(Cf. Calmon, Pedro. "Averda de das minas de prata". Em: Alencar, José de. As minas de prata. Ob. cit.: 19-25.)

"(: 19.)

(Cf. Moisés, Massaud. His tória da literatura brasileira, vol. 2. São Paulo: Cultrix Edusp, 1984: 95.) que é o caso do próprio Robério Dias*; ou melhor: por fixálos à sua época respeitando-lhe as convenções. No campo da imaginação literária, significa dizer que essas personagens ganham uma "dimensão sentimental”; que elas

humanizam-se com o traço hipotético da vida que não viveram; penetram-se da poesia retardatária dos amores e das lutas em que nunca pensaram; voltam ao palco dos acontecimentos interpretados literariamente $[\ldots]$ Adquire $[\mathrm{m}]$ a liberdade de ser tudo o que o autor quer que [elas sejam].*

Assim, pode a realidade estética de As minas de prata influir no problema do conhecimento histórico relativo à verdade do acontecido. Mas é preciso deixar de lado todo efeito de superfície, formal, para se ocupar necessariamente da estrutura profunda - aqui considerada em sua relação de verdade com o mundo, ou seja, como "visão de mundo" que, antes de ser absoluta ou designar uma representação em lugar de outra, será enunciativa à luz geral do devir.

Em José de Alencar, a história deve, pois, ser encarada apenas como objeto estético. Por isso, a importância central da imaginação poética na reformulação do pensamento historiográfico. É o que explica o desconforto da crítica ante a forte presença do “inverossímil” em seus romances: há neles, com efeito, um quê de fabuloso. E seu estudo formal o atesta: cenas repetidas, um sem-número de aparições e feitos espetaculares.

Daí vêm os equívocos, de toda espécie, no estudo da obra ficcional alencarina. E por ser tão vasta, costuma extrair-selhe a linha média a partir de um ou dois livros: ora os indianistas O guarani e Iracema, ora os urbanos Lucíola e Senhora. O que leva a crítica a recorrer aos mesmos jogos de análise, intensificando o elogio pomposo ou o juízo mais severo. E a matéria de que geralmente tratam não é senão a imaginação larga e fértil de José de Alencar.

Sob tal perspectiva, a crítica viu como defeito sua idealização do índio e a descrição portentosa da natureza. Dizem que, por isso, Alencar se tornou repetitivo; que lhe faltou o toque duro da realidade; e que seu gosto pelas coisas nacionais teria por traço a xenofobia*. Entretanto há também os que procuram lhe devassar, quando muito, a estrutura profunda da obra: como fez Alceu Amoroso Lima, o qual, ajustando-a ao organicismo hegeliano, distinguiu-lhe uma "vi- 
são cósmica e profética da realidade total"*. É preciso, todavia, que não se perca de vista a real dimensão deste admirável estudo de Alceu Amoroso Lima: "Alencar é muito mais capaz de ser compreendido por um supra-realista de 1965 do que por um realista de $1885[\ldots]$ ”**; e ainda José Aderaldo Castello, ao sistematizar os romances indianistas dentro de uma visão estritamente evolucionária."

Daí o equívoco de Augusto Meyer, que diz não haver nem romances nem personagens históricas em Alencar: é que a imaginação a tudo "transfigura", designando "sentido fabuloso" em ambiente de "intemperança fantasista”* . A escrita da história seria impossível, de vez que a fábula precederia o fato bruto, limitando a ficção alencarina a um vazio adolescente. O que também implica o juízo mais grave: o de que esta não defenderia um princípio geral, uma tese; que estaria voltada sobre si mesma, revelando mais forma que conteúdo. Mas se a arte constitui "fonte segura", como mostrou Duby, por que o contrário não se daria? Por que as fontes tratadas esteticamente não expressariam, de pleno direito, a historicidade mesma dos fatos? Sob esse ângulo, o problema mostra ser de ordem enunciativa mais que propriamente formal.

Esquecem-se, portanto, do Alencar mais filósofo, menos historiador. Porque a reminiscência alencarina diz respeito ao modo pelo qual se enuncia o "brasileiro", sua universalidade. Daí constituir o indianismo aquisição estética fundamental, doando a uma jovem nação, cujo destino começava a se decidir, os sentimentos civil e poético necessários. Tem razão Nelson Werneck Sodré quando diz ser "o indianismo [...] uma tendência universal do romantismo"*, pois foi através do elemento aborígine (da natureza) que José de Alencar nos pôs alinhados à esfera superior da civilização e da cultura. E ainda que nele o padrão seja importado, que a memória soe por vez estranha, sua dramatização das fontes revela senso estético profundo no asseio da "identidade nacional".

Mas identidade que é movediça, uma vez que "tudo passa sobre a terra” (Iracema). Do contrário, a imagem estética das coisas locais expressaria, por definitivo, um "retrato do Brasil”*. Todavia as fontes são revitalizadas conforme lhes ponham em enredo paisagens e personagens. Tal fato nos leva à conclusão de que Alencar, em sua história nacional,
"(Lima, Alceu Amoroso. “Jo. sé de Alencar, esse desco. nhecido?". Em: Alencar, José de. Iracema. Ed. do centená. rio. São Paulo: MEC/Instituto

*(:65.)

"(Castello, José Aderaldo. “Iracema e o indianismo de Alen. car". Em: Proença, M. Caval. canti. Afortuna crítica de Iracema. São Paulo: Edusp, 1979: 212.15.)

"(Meyer, Augusto. "Alencar e a tenuidade brasileira". Em: Alencar, José de. Obras completas, vol. II. Rio de Ja. neiro: Aguilar, 1964: 11-24.)

'Sodré, Nelson Werneck. "Posição de José de Alen. car". Em: Alencar, José de. Alfarrábios e Guerra dos mas. carrabios e Guerra dos mas. cates. Ed. comemorativa. Rio de Janeiro: José Olympio,
1977: xxi.)

'(Proença, M. Cavalcanti. Estudos literários. Rio de Janeiro: José Olympio, 1971: 45.) 
(Helena, Lucia. "Alencar, o discurso fundador e os pac. tos da nacionalidade". Em: Reis, L. F. (org). Fronteiras do literário Niterói: EdUFF, 1997: 166.)

"Casasanta, Mário. “Alen car-um formador de brasileiros". Em: Alencar, José de. Alfarrábios. Rio de Janeiro: José Olympio, 1957: 11.)

"Helena, Lucia. "Alencar, o discurso fundador e os pac tos da nacionalidade". Ob. cit.: 166.) não tem por assunto primeiro o mito do começo ou fim (ou "Deus ômega"); faz melhor: toma-o como "suporte estético"; desloca-o de seu lugar, criando a idéia de uma unidade nacional ou discurso fundador. Daí a noção do mito ser tão-somente enunciativa, ou seja, como "corpo de escrita e de textualização"*.

A obra ficcional alencarina põe à luz nossa historicidade em linguagem poética vasta e profunda. Essa linguagem, que acolherá o sentido fundamental de um e outro signo, deve então ser entrevista como "origem" de toda enunciação. Assim, a cada escolha de tema e tipos de personagem, na descrição da natureza e dos costumes, a história nacional, sob novo entendimento e ao infinito, torna-se. Alencar, em verdade, foi mais longe, dado que,

impondo-nos as suas criaturas, com a empolgante sugestão de sua arte, proporcionou-nos uma noção preciosa, e vem a ser que pode haver homens capazes de ampliar as dimensões humanas, no sentido da sabedoria, da heroicidade ou da santidade. Ele acreditou no homem, atribuindo-lhe reservas estranhas de energia."

Por tal motivo, diz-se que sua ficção é inacabada. É que ela percorreu, de modo profundo, o senso do real; no entanto, por causa da aliança entre história e poesia, dá-nos a falsa impressão de que seria frágil. Ao contrário: ela, como enunciado que é, esclarecerá a "face oculta” e "verdadeira” do discurso que a ilumina, o que explica, neste, o padrão estético elevado. E esse discurso,

formulado e reformulado de modo duradouro na literatura brasileira, [criará] um lugar de inscrição e de interpretação da história nacional, capaz de administrar o imaginário cultural do Romantismo e de lançar-se para além dele."

O tratamento estético da história nacional estimará a universalidade brasileira: indianismo e/ou medievalismo (âmbito global) relacionados à natureza e ao tipo de vida nos trópicos (âmbito local). O que pode ser expresso não só pelo traço psicológico do indígena (demonstração de coragem, fidelidade e pureza), como por cenas que sugerem a vivência de outro tempo e lugar (por exemplo, as "justas”, em As minas de prata). De qualquer forma, não se afastará do que Duby mostrou em Guilherme Marechal, salvo as particularidades de uma e outra situação: neste caso, a biografia poética de um cavaleiro inglês influindo decisivamente na reminiscência francesa. 
A seu modo e com rigor, a história nacional de Alencar em nada reflete a intransigência do juízo nativista; também não tem a pretensão de estabelecer o lugar do mito ou a escatologia do próprio mundo ${ }^{3}$; ou ainda reforçar o monstro do americanismo ${ }^{4}$, posto que sugerisse a América como "berço da humanidade”* Q Quanto ao nativismo, o próprio Alencar, no prefácio de Sonhos d'ouro, afasta-o de penetrar o âmago da vida nacional:

A importação contínua de idéias e costumes estranhos, que dia por dia nos trazem todos os povos do mundo, devem por força de comover uma sociedade nascente, naturalmente inclinada a receber o influxo de mais adiantada civilização.

[... e a pouco e pouco vão diluindo-se para infundir-se n'alma da pátria adotiva, e formar a nova e grande nacionalidade brasileira. ${ }^{*}$

Em tal ponto de vista, pode-se dizer que, em Alencar, não é o nativismo elemento básico. A este oporemos a categoria "progresso". Algum apreço do escritor pela moderna civilização contrasta, de fato, com o Alencar das matas, o Alencar "ecólogo”, esse Alencar dúbio que liga o elogio do recato florestal à idéia de comunidade civil: mas é onde a natureza desempenha papel central no ato civilizador. E não se engane aquele que toma o progresso, aqui, como movimento retilíneo - sua verificação é simplesmente impossível em José de Alencar. O mesmo vale para a noção de uma dialética profunda.

Não é porque o princípio do sic et non seja essencial no pensamento romântico que a obra alencarina reforça o lema do "isto ou aquilo"*. Contradições há, entretanto nada ga-
" (Alencar citado por Lima, Alceu Amoroso. "José de Alencar, esse descone de do?". Ob. cit.: 63.)

" (Alencar, José de. "Benção paterna". Em: Sonhos d'ouro. Rio de Janeiro: José Olympio, 1953: 35.)
- (Cf. Paz, Octavio. Signos em rotação. São Paulo: Perspec. tiva, 1990: 41.)

${ }^{3}$ Acerca das conquistas civilizacionais, diz Alencar: "A intervenção divina é infalível. Outrora se manifestou pelo dilúvio. Chegará a vez da combustão” (Alencar citado por Lima, Alceu Amoroso. “José de Alencar, esse desconhecido?”. Ob. cit.: 66-8). Tal sentença só é tomada, e erroneamente, em sua acepção transcendentalista, quando, na verdade, mostra o caráter extemporâneo do pensamento alencarino: José de Alencar aventa o extermínio da comunidade planetária em razão de seu crescimento desenfreado e avassalador (fome, guerras, epidemias, degradação ambiental etc.). Falando assim, não diferirá do mais pessimista ativista ecológico.

${ }^{4}$ Com efeito, Alencar não concebia a América pré-histórica dentro de uma visão que ultrapassasse a da ciência etnográfica, como a de uma "América alfa" (cf. Freixieiro, Fábio. Literatura brasileira: diversos/dispersos. Rio de Janeiro: Tempo Brasileiro, 1980: 126-29). Neste ponto, diverge de um Guérin, que, por sua vez, ambicionava "ascender às origens da humanidade $[\ldots]$ para descobrir o "ponto de partida da vida universal”, citado por Wellek, René. Conceitos de crítica. São Paulo: Cultrix, s/d: 158). 
"Amora, Antônio Soares. literatura brasileira, v. 2. São Paulo: Cultrix, 1977: 280.)
"Helena, Lucia. "Terra fértil, bom selvagem", Letteratura trale, Roma: Butzoni Edito re, ano VI, no. 66, 1996: 151.) rante a necessária supressão do Outro no choque de idéias, a fim de que brote daí uma "unidade global”: é o caso de reconhecer em Moacir a expressão de uma síntese ${ }^{5}$ e, por extensão, um “poema simbólico” em Iracema*. Se assim fosse, encarar-se-ia o devir como algo evolucionário, isto é, núcleo de historicidade que se adensa na superação de seus elementos constitutivos.

Em outras palavras, a cronologia, sem que se avance ou recue pela linha do tempo, esbate-se. A temporalidade alencarina - o Estado-nação à luz da própria natureza - enuncia o sentimento pátrio como "ato civilizador". Assim sendo, elidese tanto a visão de um progresso retilíneo (ou circular) quanto a fixação, pelo mito, de uma origem primeira. Só isso pode explicar a cincada de Antônio Soares Amora, o qual nega haver, em Iracema, uma dimensão trágica, enxergando também aí um novo Gênesis*. Em todo caso, a "naturalização do histórico” (a tal relação de forças, no consórcio entre brancos e índios) e a celebração da natureza ("historicização do natural”) têm por tarefa básica reforçar a visão de história em José de Alencar.

"E, finalmente, enunciam uma fábula que simula repetir a História”* . De um lado, a história em si mesma, como expressão social ou argumento sacado das fontes; mas sobretudo como "identidade nacional”, a ser então reescrita pelo fazer literário; do outro, o mito, influindo, como força estética e diretamente, na sensibilidade local (ou global).

É na "mina de cada palavra", portanto, que a obra alencarina recebe nova "experimentação”, e sobre a qual a crítica, a plena força, deve debruçar-se. Na história muito particular do romancista, a vida nacional recomeçando a cada instante como "fato existencial básico" ${ }^{-}$ou sua mina a ser descoberta para sempre.

Diz Castello: "Por isso é que (em Iracema) um instante supremo de síntese que se compõe do caráter e da sentimentalidade daqueles que desaparecem, para serem continuados pelos que nascem. Compõe-se ou recompõe-se simultaneamente a lenda [...] em busca de raízes para a apreensão acentuadamente lírica do instante originário da formação do seu povo". Castello, José Aderaldo. "Iracema e o indianismo de Alencar". Ob. cit.: 214-5.

${ }^{6}$ Tomamos de empréstimo a Hannah Arendt tal expressão, que aqui deve significar a imanência de todo acontecimento (ver Arendt, Hannah. $A$ vida do espírito: o pensar, o querer, o julgar. Ob. cit.: 201-3). 


\section{Marcelo Peloggio}

Doutorando em Literatura Brasileira e Teorias da Literatura pela Universidade Federal Fluminense (UFF). É também professor substituto de Literatura Brasileira pela mesma instituição. Recentemente, publicou pela revista Arte da Escrita, da Bahia, o artigo "Alencar: sem alfa e ômega”.

\section{Resumo}

O presente ensaio tem por objetivo articular uma ligação entre fato e Palavras-chave José de Alencar fato/ficção ficção, analisando os elementos do romance histórico As minas de prata, de José de Alencar. Também busca, a partir daí, indicar a presença no âmbito local de fatores universais, sugerindo que a representação das coisas nacionais ultrapassa, e muito, sua compreensão primeira.

\section{Abstract}

This essay aims at articulating a connection between fact and fiction, analyzing the elements of the historical novel As minas de prata, by José de Alencar. Furthermore, this essay also intends to indicate the presence of universal factors in the local realm, suggesting that the representation of national things surpasses a first understanding a great deal.

\section{Résumé}

L'essai a comme but articuler une possible liason entre fait et fiction, analysant les éléments du roman historique As minas de prata, de José de Alencar. L'essai cherche aussi à indiquer la présence de traits universels à partir de caractères locaux, tout en envisageant la représentation des choses nationales qui vont au-delà d'une compréhension initiale.
Key words

José de Alencar fact/fiction local/universal

Mots-clés José de Alencar fait/fiction local/universel

Recebido em $30 / 09 / 2003$

Aprovado em 